\title{
GESTÃO DE RESÍDUOS SÓLIDOS: DIFICULDADES E POTENCIALIDADES EM UM CONSÓRCIO INTERMUNICIPAL
}

\section{SOLID WASTE MANAGEMENT: CHALLENGES AND POTENTIALITIES IN}

\section{AN INTERMUNICIPAL CONSORTIUM}

Versão do autor aceita publicada online: 27 jan. 2022

Publicado online: 16 fev. 2022

Como citar esse artigo - American Psychological Association (APA): Knopf, D. dos S. Lorenzi Junior, D., Pontelli, G. E. \& Kneipp, J. M. (2022). Gestão de resíduos sólidos: dificuldades e potencialidades em um consórcio intermunicipal. Exacta. DOI: https://doi.org/10.5585/exactaep.2022.20776.

\section{Débora dos Santos Knopf}

deboraknopf@hotmail.com

https://orcid.org/0000-0001-5867-1884

Universidade Federal de Santa Maria / RS

Mestra em Gestão de Organizações Públicas, Universidade Federal de Santa Maria,

Santa Maria, Brasil.

\section{David Lorenzi Junior}

davilorenzi@yahoo.com.br

https://orcid.org/0000-0002-0358-6823

Universidade Federal de Santa Maria / RS

Professor, Departamento de Ciências Administrativas, Universidade Federal de Santa Maria, Santa Maria. Brasil.

\section{Greice Eccel Pontelli}

grace_pontelli@yahoo.com.br

https://orcid.org/0000-0003-4643-478X

Universidade Federal de Santa Maria / RS

Doutoranda, Programa de Pós-Graduação em Administração, Universidade Federal de Santa Maria, Santa Maria, Brasil.

\section{Jordana Marques Kneipp}

jordana.kneipp@ufsm.br

https://orcid.org/0000-0001-6982-994X

Universidade Federal de Santa Maria / RS

Professora do Departamento de Ciências Administrativas da Universidade Federal de Santa Maria, Santa Maria, Brasil.

Resumo: Este estudo tem por objetivo descrever as principais dificuldades e potencialidades observadas na gestão de resíduos sólidos no Consórcio Intermunicipal de Gestão de Resíduos Sólidos (CIGRES). Para tanto, foi realizada uma pesquisa descritiva com abordagem qualitativa. Os dados foram coletados por meio de entrevistas e análise documental, tendo sido utilizada a técnica de análise de conteúdo para a sistematização 


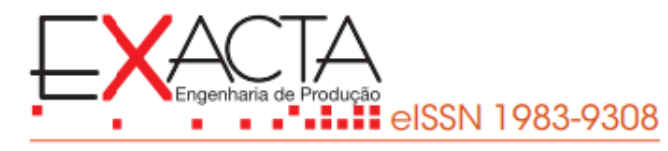

dos dados. Os resultados apontaram dificuldades, potencialidades e alguns aspectos que precisam ser repensados na gestão dos resíduos sólidos. Ademais, constataram-se aspectos positivos em relação à preocupação com o tripé da sustentabilidade. Ao entrelaçar o conhecimento acadêmico com o caso prático do CIGRES, o estudo traz contribuições teóricas sobre a temática da sustentabilidade e a gestão de resíduos sólidos. No que concerne às contribuições gerenciais, os resultados fornecem evidências empíricas sobre a gestão dos consórcios, bem como auxilia os formuladores de políticas públicas. Sendo assim, esta pesquisa contribui com a Agenda 2030.

Palavras-chave: Consórcio. Gestão de resíduos sólidos. Municípios. Sustentabilidade.

Abstract: This study aimed to describe the main challenges and potentialities observed in solid waste management in the Intermunicipal Solid Waste Management Consortium (CIGRES). Therefore, descriptive research with a qualitative approach was carried out; data were collected through interviews and document analysis using the content analysis technique to systematize the data. The results pointed out the challenges, potential, and some aspects that must be rethought in solid waste management. Furthermore, there were positive aspects regarding the concern with the sustainability tripod. By interlacing academic knowledge with the practical case of CIGRES, this study provides theoretical contributions on the theme of sustainability and solid waste management. With regard to managerial contributions, the results provide empirical evidence on consortium management as well as helping public policymakers. Therefore, this research contributes to the 2030 Agenda.

Keywords: Consortium. Solid waste management. Municipality. Sustainability. 


\section{Introdução}

Considerando o aumento dos níveis de produção e de consumo e o crescimento da população, a geração de resíduos tem aumentado significativamente a cada ano, tanto por parte dos consumidores quanto dos fabricantes. Em países em desenvolvimento, como o Brasil, isso pode causar graves impactos ao meio ambiente e à saúde pública (Pereira \& Fernandinho, 2019). Ao mesmo tempo, o poder público tem sido o principal responsável pela correta gestão desses resíduos, mas esse é um problema que diz respeito a todos os cidadãos e à sociedade (Almeida, Silveira \& Engel, 2020).

Diante desse cenário, a Política Nacional de Resíduos Sólidos (PNRS) foi instituída pela Lei no 12.305 , de 2 de agosto de 2010, como forma de solucionar a problemática dos resíduos sólidos, a qual tem afetado as cidades brasileiras. A referida lei determina a criação de um plano de gestão dos resíduos sólidos, o qual pode ser estadual, regional ou municipal, desde que atenda aos objetivos estabelecidos na norma. Entretanto, mesmo tendo sido promulgada em 2010, ainda existem grandes desafios para que os municípios brasileiros se adequem a essa lei (Pereira \& Fernandinho, 2019).

O descaso para com o gerenciamento dos resíduos sólidos deriva do processo de urbanização e pode comprometer o meio ambiente e a qualidade de vida da população (Almeida, Silveira \& Engel, 2020). Sendo assim, o descarte de resíduos sólidos requer atenção especial, principalmente em função de sua complexidade e seu crescente volume (Pereira \& Fernandinho, 2019). Nesse sentido, enfatiza-se o papel dos gestores públicos em propor planos e assegurar a correta destinação dos resíduos sólidos urbanos (RSU). Porém, municípios de pequeno e médio porte não possuem recursos financeiros nem corpo técnico suficientes para uma gestão eficiente e sustentável dos resíduos sólidos (Ventura \& Suquisaqui, 2019). Essas dificuldades e o rigor da legislação ambiental são aspectos que vêm impulsionando os munícipios a formarem consórcios públicos em busca de soluções que otimizem recursos humanos e financeiros e a proteção ambiental (Gomes et al., 2017).

Nesse sentido, os estados ou as microrregiões podem criar consórcios intermunicipais para a gestão dos resíduos sólidos. Esses consórcios devem viabilizar a união entre dois ou mais entes da federação (municípios, estados e União), não ter fins lucrativos e possuir a finalidade de prestar serviços e desenvolver ações conjuntas, visando ao interesse coletivo e aos benefícios públicos (Saffer, et al., 2013). A gestão compartilhada é um dos pontos-chave da PNRS (Heber \& Silva, 2014). 
Segundo dados do Sistema Nacional de Informações sobre Saneamento (SNIS, 2019), em 2018, a atuação dos consórcios como operadores de resíduos sólidos representava somente $0,9 \%$, contando com 37 unidades no Brasil. A grande parte era operada pela administração pública - nesse caso, pelas prefeituras municipais $(61,2 \%)$. Com isso, observa-se que a atuação dos consórcios ainda não é uma realidade comum no país.

A temática vem sendo discutida na literatura a partir das seguintes perspectivas: inclusão socioprodutiva de catadores (Fidelis et al., 2020); avaliação e gestão sustentável (Liikanen et al., 2018; Pereira \& Fernandinho, 2019), da eficácia da PNRS (Cetrulo et al., 2020); contexto da pandemia de covid-19 (Penteado \& Castro, 2021). Os estudos de Lisbinski et al. (2020) e de Calderan $(2013 ; 2018)$ enfatizam os consórcios para a gestão de resíduos sólidos. Já Heber e Silva (2014) destacam os desdobramentos da PNRS, abordando seus desafios, soluções próprias e outros elementos de contexto.

A criação de consórcios intermunicipais e a adesão pelos municípios brasileiros devem ser incentivadas. Ao mesmo tempo, os municípios devem receber um montante maior de investimentos para que os consórcios consigam, de fato, realizar a gestão dos resíduos sólidos e atender às diretrizes determinadas na PNRS (Zago \& Barros, 2019). Assim, tanto os consórcios como os municípios pequenos devem trabalhar juntos para eliminar os desafios e as barreiras existentes e, principalmente, para encontrar uma disposição final dos resíduos ambientalmente correta.

Portanto, considerando que a prática de consórcio pode ser uma opção para a gestão efetiva dos resíduos sólidos - principalmente na região do Médio Alto Uruguai, por abranger um dos principais consórcios do estado do Rio Grande do Sul, o Consórcio Intermunicipal de Gestão de Resíduos Sólidos (CIGRES) -, apresenta-se o seguinte problema de pesquisa: quais as dificuldades e as potencialidades que o Consórcio em estudo tem enfrentado na gestão dos resíduos sólidos junto aos municípios consorciados? Com a finalidade de responder ao problema de pesquisa, este estudo tem por objetivo descrever as principais dificuldades e potencialidades observadas na gestão de resíduos sólidos no Consórcio Intermunicipal de Gestão de Resíduos Sólidos (CIGRES), localizado no município de Seberi-RS. Considerando a importância da temática em estudo, a pesquisa busca contribuir com a literatura, identificando aspectos que precisem ser aprimorados e evidenciando reflexos positivos da correta gestão de resíduos sólidos urbanos. Do ponto de vista gerencial, os resultados permitem avaliar os gestores da 
organização em estudo e ampliar/inserir ações e práticas que sirvam de incentivo para outros municípios.

Além da introdução, este texto está estruturado em outras cinco seções. Na seção 2, é apresentada a revisão de literatura sobre gestão de resíduos sólidos que balizou a pesquisa. Na seção 3, apresenta-se o método utilizado para operacionalizar o estudo. Na seção 4, são demonstrados os resultados e, na seção 5, são expostas as considerações finais. Por fim, são expostas as referências.

\section{Gestão de resíduos sólidos}

Em países em desenvolvimento, a gestão dos resíduos sólidos é uma atividade complexa. Além de aspectos econômicos e ambientais, ela engloba o aspecto social, representado pelo catador. O catador é um trabalhador informal da cadeia da reciclagem que participa ativamente da coleta, da classificação e da comercialização de resíduos sólidos urbanos com potencial reciclável (Fidelis et al., 2020). No Brasil, muitos municípios apresentam dificuldades para gerenciar seus resíduos sólidos de forma sustentável (Pereira \& Fernandinho, 2019). Até agora, a disposição em aterro tem sido o método de tratamento predominante para os RSU em todo o Brasil (Liikanen et al., 2018).

Para conduzir os resíduos sólidos, a integração entre as várias fases do gerenciamento (classificação, cóleta, transporte e destino final) é fundamental (Pereira \& Fernandinho, 2019). A gestão compartilhada tem sido um mecanismo adotado para minimizar os problemas relacionados à destinação dos resíduos sólidos urbanos (Ventura \& Suquisaqui, 2019) e um dos principais pontos da Política Nacional de Resíduos Sólidos (Heber \& Silva, 2014).

A fim de melhorar a gestão dos RSU, a administração pública municipal pode utilizar medidas para melhorar o desempenho da gestão de RSU, tendo como base o uso de indicadores e ferramentas de controle de gestão (Ventura \& Suquisaqui, 2019). Em complemento, Pereira e Fernandinho (2019) destacam o uso de indicadores de sustentabilidade, os quais podem ser calculados por gestores públicos e funcionários municipais do setor de resíduos sólidos.

Pereira e Fernandinho (2019) apontam, ainda, a necessidade de um bom plano de gestão de RSU e uma estratégia de gestão do território para identificar como avaliar a qualidade da gestão dos resíduos sólidos em um quadro adequado às necessidades e ao contexto do município. Leal e Sampaio (2021) acentuam que os municípios ainda estão 
nas primeiras iniciativas em relação à governança ambiental, havendo carências de capacidade técnica, de estruturação de órgãos, conselhos, legislações e fundos, sobretudo para o real funcionamento desses elementos.

Os consórcios intermunicipais têm sido uma das opções que os pequenos municípios têm utilizado para atender à legislação e prestar um serviço de qualidade. Embora possam ser a opção mais adequada para a disposição final dos resíduos dos pequenos municípios, é preciso que os gestores e líderes locais estejam engajados e comprometidos para a consolidação dos consórcios (Luiz, 2018).

\subsection{Consórcios públicos e a gestão de resíduos sólidos}

Os consórcios se apresentam como uma solução viável para os municípios que buscam alternativas de locais para a disposição final dos resíduos e ganho de escala, otimizando os recursos e o tratamento dos resíduos (Ferreira \& Jucá, 2017). O Decreto no 6.017, de 17 de janeiro de 2007, que regulamenta a Lei $\mathrm{n}^{\mathrm{o}}$ 11.107, de 6 de abril de 2005, apresenta a seguinte definição de consórcio público:

Pessoa jurídica formada exclusivamente por entes da Federação, na forma da Lei $\mathrm{n}^{\circ} 11.107$, de 2005, para estabelecer relações de cooperação federativa, inclusive a realização de objetivos de interesse comum, constituída como associação pública, com personalidade jurídica de direito público e natureza autárquica, ou como pessoa jurídica de direito privado sem fins econômicos (Brasil, 2007).

O consórcio gera emprego e renda na região, diminui os gastos dos municípios na destinação dos resíduos sólidos urbanos, possibilita o acesso dos municípios a esse serviço público e atua na sensibilização da população sobre desenvolvimento sustentável por meio de coleta seletiva, reciclagem e diminuição de resíduos sólidos gerados (Lisbinski et al., 2020). Jacobi e Besen (2011) complementam que os consórcios viabilizam o aumento da capacidade de gestão dos resíduos e a redução dos custos referentes à coleta, ao tratamento e à destinação final dos RSU. Ademais, criam mecanismos de inclusão de associações e catadores de recicláveis. É possível criar consórcios, por exemplo, apenas para a gestão de um aterro sanitário, para equipamentos ou veículos ou só para os serviços de coleta dos resíduos (Saffer, et al., 2013).

Vários podem ser os benefícios da adesão aos consórcios, como o desenvolvimento sustentável, a diminuição de custos e gastos públicos (Alves et al., 2020; Lisbinski et al., 2020), o aprimoramento da gestão municipal e a melhoria da 
limpeza urbana e da qualidade de vida da população (Lisbinski et al., 2020). Na visão de Calderan (2013), existe um ganho de eficiência tanto para a gestão quanto para a execução das políticas relacionadas aos RSU.

Aos municípios integrantes, compete definir as prioridades, os investimentos e o planejamento, buscando uma visão estratégica para resolver a destinação dos RSU de forma conjunta, considerando aspectos econômicos, sociais e ambientais (Ferreira \& Jucá, 2017). A construção de um aterro consorciado, por exemplo, torna-se benéfica, visto que possibilita a redução de grandes percentuais dos custos relacionados à disposição final de RSU (Alves et al., 2020).

O estudo de Calderan (2013), realizado no CIGRES, apontou que os municípios integrantes reconhecem que o consorciamento auxiliou na prestação dos serviços e no desenvolvimento da microrregião, trazendo ganhos econômicos, administrativos e ambientais, bem como sociais.

Conforme o art. 52 do Decreto no 7.404/2010 (Brasil, 2010b), ao optarem pela gestão de forma consorciada, os municípios estão dispensados da elaboração do plano municipal de gestão integrada de resíduos sólidos - desde que o plano intermunicipal atenda ao conteúdo mínimo previsto na Lei da PNRS (Brasil, 2010a). Ainda, a PNRS prevê, junto ao Governo Federal, a priorização de repasses e recursos para os consórcios.

Deus et al. (2020), por meio de um indicador ambiental, constataram que os municípios precisam desenvolver e implementar práticas que envolvam a reciclagem de forma mais eficiente e eficaz. Ademais, devem aperfeiçoar os processos de coleta, armazenamento e triagem dos resíduos, integrando os catadores e aprimorando sua formação técnica, viabilizando, assim, maior inclusão social e participação integrada na gestão dos RSU.

\section{Procedimentos metodológicos}

A presente pesquisa se caracteriza como um estudo de caso, pelo fato de ter sido realizada junto ao Consórcio Intermunicipal de Gestão de Resíduos Sólidos. Segundo Yin (2015), o estudo de caso pode ser aplicado em várias situações, desde os contextos político e organizacional até pesquisas em instituições públicas, permitindo um detalhamento maior da temática investigada.

Dessa forma, este estudo tem por objetivo descrever as principais dificuldades e potencialidades observadas na gestão de resíduos sólidos no Consórcio Intermunicipal de 
Gestão de Resíduos Sólidos (CIGRES). Optou-se pela análise do consórcio CIGRES pelo fato de ser um dos principais consórcios do estado do Rio Grande do Sul. Ademais, ele contempla grande parte dos municípios consorciados de pequeno porte (foi utilizada a definição de municípios de pequeno porte nível I: municípios com uma população de até 20 mil habitantes, conforme definido pelo Censo do IBGE de 2010).

Para isso atingir o objetivo proposto, utilizou-se uma abordagem qualitativa do tipo descritiva (Sampieri, Collado \& Lucio, 2013). A coleta de dados foi realizada por meio de entrevistas semiestruturadas (Anexo A) e análise documental. Inicialmente, foi realizado o contato com os gestores, solicitando autorização para a pesquisa. As entrevistas foram realizadas com 2 responsáveis ligados à gestão dos resíduos sólidos do CIGRES, o Diretor Técnico e o Supervisor Operacional, ambos profissionais especializados e com experiência na área investigada. O roteiro da entrevista foi formulado com base na Lei Federal n⿳0 12.305/2010 - que determina a Política Nacional de Resíduos Sólidos -, no modelo estabelecido e proposto pelo Consórcio Intermunicipal de Gestão de Resíduos Sólidos (CIGRES, 2012) e no modelo estabelecido por Calderan (2013).

A coleta dos dados ocorreu durante o mês de maio de 2020, em condições convenientes para os entrevistados, nas instalações do consórcio. As entrevistas foram gravadas, transcritas e analisádas. Para garantir a integridade e o bem-estar dos participantes, eles foram designados como E1 e E2. O entrevistado E1 ocupa o cargo de Diretor de Projetos e Engenheiro Sanitarista e Ambiental, tendo formação em Engenharia Sanitária e Ambiental. Já o entrevistado E2 ocupa o cargo de Supervisor Operacional e tem o Ensino Superior Incompleto.

Para a análise dos dados, foi utilizada a técnica de análise de conteúdo, organizada em três polos cronológicos: (1) a pré-análise; (2) exploração do material; e (3) o tratamento dos resultados, inferência e interpretação (Bardin, 2016).

\section{Resultados e discussões}

\subsection{Caracterização do consórcio}

O Consórcio Intermunicipal de Gestão de Resíduos Sólidos (CIGRES) é responsável pelo tratamento e pela destinação final adequada dos resíduos sólidos 
domésticos. O CIGRES é um consórcio público localizado no município de Seberi-RS, tendo sido constituído em setembro de 2001. No entanto, somente em 12 de março de 2007 iniciou sua operação, atendendo apenas três municípios (Calderan, 2013). Atualmente, o CIGRES possui 31 municípios pertencentes à região do Alto Médio Uruguai, Rio da Várzea e região Celeira (CIGRES, 2019).

O Estatuto do Consórcio (CIGRES, 2010) prevê a estrutura básica da Administração, qual seja: (I) Assembleia Geral; (II) Conselho de Prefeitos; (III) Conselho Fiscal; (IV) Secretaria Executiva e (V) Câmaras Setoriais. Em relação à estrutura, o consórcio possui 83 funcionários na composição do quadro funcional. Cerca de $90 \%$ do quadro funcional é composto por operários, operadores de máquina e motoristas, os quais trabalham diretamente no processo de triagem, armazenamento, tratamento e destino final dos resíduos sólidos. O que não é triado, vai para o aterro sanitário.

De acordo com o E1, o consórcio recebe resíduos residenciais, de pequenos comércios e de locais públicos, sendo que não é recebido nenhum tipo de resíduo de mineração, industrial, hospitalar ou outro tipo de resíduo. Ainda, o E1 enfatiza que a administração e a estrutura estão melhores se comparadas a períodos anteriores.

Sobre a quantidade de funcionários, o E2 menciona que o consórcio está praticamente com um número excedente de funcionários; pois, antigamente, o CIGRES trabalhava em dois turnos. Após a avaliação de custos de operacionalização em dois turnos, observou-se que era praticamente inviável trabalhar dessa forma. Logo, os funcionários foram realocados para um turno único, sendo possível atender à demanda (E2). O E1 destacou que o CIGRES, dentro do tripé da sustentabilidade, sempre procura atender o social, o ambiental e o econômico, observando o equilíbrio entre as três dimensões. O aspecto social também é evidenciado por Calderan (2013), Fidelis et al. (2020) e Deus (2020). A respeito da dimensão social, o E1 destaca:

\footnotetext{
Mas a gente (o consórcio CIGRES) também sempre pensa muito no aspecto social né, a gente sabe que são 83 empregos diretos, só aqui dentro né, mas vai ligar toda a cadeia, é o mercado, mais os familiares, hoje passa de 2 mil empregos indiretos aqui fácil. E isso é muito importante (E1).
}

Ainda sobre o trabalho do consórcio, inicialmente, os resíduos passam pela triagem para seleção; em seguida, são separados para venda, e o material descartado vai para o aterro sanitário. Os resíduos com maior valor comercial agregado são: papel; papelão; metal e sucata no geral; vidro; plástico; e garrafas pet (E1). 
Recentemente, foi construído um aterro impermeabilizado, conforme as exigências das NBRs (Normas Brasileiras) e demais leis vigentes. Conforme consta no PIGIRS do CIGRES (2019), a área do aterro sanitário é de 1,5 hectare e, segundo o E1, ele possui 3,83 anos de vida útil operando adequadamente. Atualmente, no que se refere ao espaço disponível, o aterro ainda está no primeiro patamar. Destaca-se que a iniciativa se torna benéfica, conforme apontam Alves et al. (2020).

Quanto à compostagem, a Fundação Estadual de Proteção Ambiental (FEPAM) interditou o pátio de compostagem por não estar atendendo a todas as normas vigentes. Atualmente, o CIGRES não realiza compostagem, e os resíduos orgânicos estão sendo enviados para o aterro sanitário (E1). Aponta-se a necessidade de repensar tal prática, visto que, conforme o E1, do total de resíduos, aproximadamente $88 \%$ têm destinação final no aterro sanitário, sendo apenas $12 \%$ destinado à reciclagem (para yenda). $\mathrm{O} E 2$ confirma a importância da compostagem para os municípios e seu impacto para o consórcio:

Em relação ao orgânico, até tem alguns municípios que já estão, já tê, a composteira municipal, e alguns municípios já estão começando com os projetos junto com a Emater (Empresa de Assistência Técnica e Extensão Rural), das composteiras aquelas que fazem em casa. Isso aí acaba indiretamente, se vir a funcionar como a gente gostaria que funcionasse, os resíduos orgânicos não viriam pra cá, e viria bem dizer, uma forma indireta da coleta seletiva (E2).

Diante disso, observa-se a importância da gestão compartilhada (Heber \& Silva, 2014) com o consórcio, podendo ser uma solução viável para o problema do gerenciamento de RSU (Ferreira \& Jucá, 2017; Lisbinski et al., 2020). Isso porque contribui para a gestão sustentável (Liikanen et al., 2018; Pereira \& Fernandinho, 2019) e para a eficácia da PNRS (Cetrulo et al., 2020). As características dos municípios integrantes do consórcio são apresentadas na Tabela 1.

Tabela 1 - Área, população total e geração de resíduos dos municípios consorciados.

\begin{tabular}{|l|r|r|r|r|}
\hline \multirow{2}{*}{$\begin{array}{c}\text { Municípios } \\
\text { Consorciados }\end{array}$} & \multirow{2}{*}{$\begin{array}{c}\text { Área } \\
\left(\mathbf{k m}^{\mathbf{2}}\right)\end{array}$} & $\begin{array}{c}\text { População Total } \\
\text { (habitantes) }\end{array}$ & \multicolumn{2}{|c|}{ Resíduos (Tonelada/Ano) } \\
\cline { 5 - 5 } & 93,49 & 7.323 & 2017 & 2018 \\
\hline Ametista Do Sul & 63,373 & 3089 & 251,61 & 238,53 \\
\hline Barra Do Guarita & 194,815 & 2.114 & 221,76 & 229,72 \\
\hline Boa Vista Das Missões & 189,203 & 5.071 & 296,53 & 297,67 \\
\hline Caiçara & 73,438 & 2.417 & 147,12 & 140,25 \\
\hline Cerro Grande & & & \\
\hline
\end{tabular}




\begin{tabular}{|c|c|c|c|c|}
\hline \multirow{2}{*}{$\begin{array}{c}\text { Municípios } \\
\text { Consorciados }\end{array}$} & \multirow{2}{*}{$\begin{array}{l}\text { Área } \\
\left(\mathbf{k m}^{2}\right)\end{array}$} & \multirow{2}{*}{$\begin{array}{c}\text { População Total } \\
\text { (habitantes) }\end{array}$} & \multicolumn{2}{|c|}{ Resíduos (Tonelada/Ano) } \\
\hline & & & 2017 & 2018 \\
\hline Cristal Do Sul & 97,715 & 2.826 & 262,67 & 171,01 \\
\hline Derrubadas & 361,171 & 3.190 & 171,71 & 177,68 \\
\hline Dois Irmãos Das Missões & 225,681 & 2.157 & 159,61 & 158,93 \\
\hline Erval Seco & 363,893 & 7.878 & 639,86 & 607,77 \\
\hline Frederico Westphalen & 264,975 & 28.843 & $6.810,73$ & $6.599,00$ \\
\hline Iraí & 180,962 & 8.078 & 867,10 & 796,85 \\
\hline Jaboticaba & 128,053 & 4.098 & 288,78 & 276,65 \\
\hline Lajeado Do Bugre & 67,933 & 2.487 & 145,08 & 146,18 \\
\hline Liberato Salzano & 245,627 & 5.780 & 370,81 & 279,62 \\
\hline Miraguaí & 130,434 & 4.855 & 375,83 & 341,75 \\
\hline Novo Tiradentes & 75,428 & 2.277 & 174,03 & 154,48 \\
\hline Palmitinho & 144,045 & 6.920 & 742,91 & 717,72 \\
\hline Pinhal & 68,208 & 2.513 & 223,31 & 206,12 \\
\hline Pinheirinho Do Vale & 105,612 & 4.497 & 318,19 & 349,54 \\
\hline Planalto & 230,42 & 10.524 & 919,67 & 938,79 \\
\hline Redentora & 302,68 & 10.222 & 385,36 & 387,62 \\
\hline Rodeio Bonito & 83,167 & 5.743 & 716,84 & 858,01 \\
\hline Sagrada Família & 78,253 & 10.897 & 195,14 & 218,57 \\
\hline São José Das Missões & 98,07 & 2.595 & 154,40 & 139,76 \\
\hline São Pedro Das Missões & 79,965 & 2.720 & 123,17 & 109,37 \\
\hline Seberi & 301,42 & 1.886 & $1.859,08$ & $1.695,33$ \\
\hline Taquaruçu Do Sul & 76,849 & 2.966 & 354,63 & 372,12 \\
\hline Tenente Portela & 337,956 & 13.719 & $1.583,98$ & $1.472,95$ \\
\hline Vicente Dutra & 193,055 & 5.285 & 315,73 & 329,47 \\
\hline Vista Alegre & 77,455 & 2.832 & 316,34 & 317,15 \\
\hline Total & $5.023,149$ & $\mathbf{1 7 8 . 5 6 1}$ & $20.277,36$ & $19.599,67$ \\
\hline
\end{tabular}

Fonte: Fonte: CIGRES (2019).

Os dados apresentados demonstram que o CIGRES abrange um total de 178.561 habitantes, e sua área corresponde a cerca de 1,64\% do território do estado do Rio Grande do Sul (CIGRES, 2019). A maioria dos municípios são de pequeno porte. Em relação à quantidade de resíduos gerada por município, observa-se um decréscimo de 20.277,36 toneladas (2017) para 19.599,67 (2018). Os municípios de Frederico Westphalen, Seberi e Tenente Portela são os que mais destinam resíduos para o CIGRES. 


\subsection{Gestão: Consórcio e Municípios}

O CIGRES se mantém com o pagamento dos municípios, das verbas municipais e das vendas dos materiais recicláveis. Para isso, há uma porcentagem em que é feito um cálculo sobre o índice de resíduos que o município entregou ao consórcio (E1). Os valores são abatidos no valor final que os municípios devem repassar ao consórcio, sendo descontadas as vendas de materiais.

Segundo o responsável, a forma de calcular é padrão para todos os municípios. O E1 enfatiza que, conforme observado no PIGIRS, o abatimento é realizado com base no valor total de receita que o consórcio teve com os recicláveis e no percentual de resíduos que cada município gerou. O abatimento é feito com base no valor total de receita do CIGRES, e não especificadamente de acordo com a quantidade exata de resíduos recicláveis que cada município enviou e que foi possível vender. A fórmula de cálculo, segundo a Resolução n- 2, de abril de 2019, consta no PIGIRS (2019) do consórcio.

Após a análise documental e o relato dos entrevistados, observou-se que não há maiores vantagens para os municípios que enviam mais resíduos recicláveis. Por outro lado, quanto maior a quantidade de resíduos recicláveis enviadas para o consórcio, maior será a receita do consórcio; consequentemente, os municípios também se beneficiam no abatimento do custo repassado pelo CIGRES.

Entretanto, o E1 chama âtenção para o fato de que é preciso repensar a sistemática, valorizando os municípios que estão trabalhando corretamente na coleta seletiva e, consequentemente, estão enviando mais resíduos recicláveis ao consórcio. Recentemente, ocorreu a padronização do valor da tonelada de resíduo. Em um segundo momento, será discutida outra alternativa para que se incentive os municípios a enviarem maior quantidade de resíduos recicláveis (E1), gratificando-os.

Quanto ao fluxo de informações, ocorre da seguinte forma: o CIGRES envia, aos municípios, as informações sobre a quantidade de toneladas geradas de resíduos, quanto disso é separado quantitativamente nas esteiras e vendido, entre outras informações. Em seguida, os municípios inserem esses dados no Sistema Nacional de Informações sobre Saneamento (SNIS).

No que concerne ao retorno financeiro das vendas, o E2 informou que apenas cerca de $12 \%$ a $13 \%$ dos resíduos são materiais que podem ser vendidos; ou seja, um percentual considerado baixo e que não compensa o custo que se tem para fazer a triagem dos resíduos. Ainda, complementa que seria necessário reduzir cerca de $50 \%$ do número 
de funcionários, para, talvez, ser possível pagar os custos do consórcio com a receita de vendas.

Conforme as informações do PIGIRS CIGRES (2019), no ano de 2017, o consórcio fez a triagem somente de $17 \%$ dos resíduos que passaram na esteira; o restante foi descartado para o aterro. O E2 menciona que o CIGRES tem se tornado referência no assunto de venda de materiais recicláveis, tendo em vista que outros consórcios buscam orientações junto ao CIGRES. Na percepção do E1, isso se deve ao fato de o CIGRES contar com uma estrutura maior, experiência mais consolidada, recursos materiais e profissionais.

Quanto ao Plano Regional de Gestão Integrada de Resíduos Sólidos, o E1 informou que todos os municípios consorciados fazem parte do plano (recentemente atualizado), cujas várias metas já foram atingidas. Segundo o E1, o Tribunal de Contas, o órgão fiscalizador, está sempre auditando as metas de acordo com o que foi projetado no plano. O documento foi atualizado no final do ano de 2019, sendo definido como Plano Intermunicipal de Gestão Integrada de Resíduos Sólidos. Na análise do relatório final, verificaram-se informações sobre a região, os municípios consorciados e as ações e metas que visam melhorar a gestão e a destinação final dos resíduos sólidos. O documento se encontra no sítio oficial do consórcio ${ }^{1}$, disponibilizado de forma pública. Em relação às vantagens do consorciamento com os municípios, destacam-se:

- Redução do custo, pois, na conjuntura atual, o município sozinho não conseguiria manter o aterro com uma estrutura que o CIGRES possui atualmente (E1);

- Diminuição de impacto ambiental, em decorrência da redução de aterros nos municípios (E1 e E2).

O CIGRES possui área licenciada, realizando todos os tipos de controle que as normas exigem. Com um único aterro para todos os 31 municípios, é possível haver maior controle por parte do consórcio, tanto na construção de indicadores e venda quanto no processo de aterro final dos resíduos. No Quadro1, são expostas as dificuldades que os entrevistados evidenciaram em relação à gestão.

Quadro 1 - Dificuldades em relação à gestão evidenciadas pelos entrevistados.

\begin{tabular}{|l|l|}
\hline \multicolumn{2}{|c|}{ Dificuldades } \\
\hline \multicolumn{2}{|c|}{ Relacionamento com os municípios consorciados } \\
$\begin{array}{l}\text { Gestão e rotatividade de funcionários das prefeituras responsáveis } \\
\text { pelos resíduos sólidos (E1 e E2); }\end{array}$ & $\begin{array}{l}\text { Sítio com poucas informações } \\
\text { (E1 e E2); }\end{array}$ \\
\hline
\end{tabular}

\footnotetext{
${ }^{1}$ CIGRES: http://www.cigres.com.br/portal/
} 


\begin{tabular}{|c|c|}
\hline \multicolumn{2}{|l|}{ Dificuldades } \\
\hline Relacionamento com os municípios consorciados & Consórcio (internas) \\
\hline Dificuldade de contato (E1); & $\begin{array}{l}\text { Processos internos e } \\
\text { administrativos do CIGRES } \\
\text { (E1). }\end{array}$ \\
\hline $\begin{array}{l}\text { "Mentalidade do profissional" responsável na gestão do município, } \\
\text { que muitas vezes falha na gestão e na conscientização ambiental } \\
\text { (E2); }\end{array}$ & \\
\hline $\begin{array}{l}\text { Problemas na coleta e no transporte de resíduos, principalmente em } \\
\text { casos que o caminhão não possui separação interna, provocando a } \\
\text { mistura dos resíduos (E1); }\end{array}$ & \\
\hline $\begin{array}{l}\text { Falta de integração das informações relativas à saneamento, à água, } \\
\text { ao esgoto e aos resíduos sólidos (plataforma online para indicadores) } \\
\text { (E1 e E2); }\end{array}$ & \\
\hline Legislação do município não é aplicada na prática (E1). & \\
\hline
\end{tabular}

Acerca do relacionamento com as prefeituras, o E2 menciona:

Eles (os profissionais das prefeituras/municípios) acabam não dando a importância devida para o ambiental sabe?. Então eles podiam, se quisessem, reduzir o custo (dos resíduos sólidos) e investir em outras áreas do município. Por exemplo, o município que paga 10 mil reais para o CIGRES, poderia pagar 9 ou 8 mil e gastar o restante, esses 2 mil, em outra área do município (E2).

Em relação à coleta de resíduos, o E1 menciona que vem melhorando e que problemas de envio de resíduos perigosos tem diminuído. Segundo ele, o trabalho realizado por secretarias e departamentos ambientais das prefeituras, pela Emater e pelas cooperativas da região tem auxiliado nesse processo.

Em questão de resíduo da saúde, não vou dizer que não vem, mas vem. Diminuiu muito. Por que? Porque a gente tem alguns parâmetros aqui (no CIGRES) pra receber os resíduos. Existe a instalação de câmeras, tem um fiscal de carga, distribuímos cartilhas e orientações para realizar essa questão da compostagem. Tudo isso, a questão de lâmpadas também, eletrônico, tudo isso, vinha muito e hoje reduziu drasticamente (E1).

Entretanto, algumas quantidades de lâmpadas, pilhas ou baterias tem sido registradas; mas quando o consórcio consegue identificar e coletar esses resíduos, tem sempre destinado corretamente tais materiais. Acerca do transporte, o E1 menciona:

[..] Aí nesse meio tempo (coleta e transporte dos resíduos) tem muitos problemas. Desde a empresa terceirizada, às vezes a gente (o consórcio CIGRES) tem que passar a informação para a prefeitura, ou seja, a gente tem que falar com a prefeitura para que ela comunique o cara (o responsável da transportadora). Aí a gente enfrenta muitas dificuldades. A gente não consegue ter um controle cem por cento, mesmo tendo câmeras, tendo o fiscal de carga, às vezes vem muito material indevido pra cá, e a gente não consegue identificar os responsáveis $(\mathrm{E} 1)$. 
No tocante às dificuldades, os entrevistados apontam que o consórcio também tem trabalhado junto a cada Emater dos municípios a fim de aproximar o contato com os municípios. Fica evidente, conforme sinalizam Leal e Sampaio (2021), que os municípios ainda estão realizando as primeiras iniciativas em relação à governança ambiental, havendo carências sobre o funcionamento e a gestão.

Para minimizar as dificuldades, o consórcio está buscando apoio do Conselho dos Prefeitos em assembleias e reuniões, enfatizando questões relacionadas à gestão dos resíduos sólidos. Os entrevistados E1 e E2 afiram que, quanto ao transporte, o CIGRES está realizando a compra de caminhões para fazer a coleta dos resíduos. O consórcio foi contemplado com R \$ 4,9 milhões, recurso oriundo de direitos difusos do Ministério da Justiça e liberado por meio de convênio com o Ministério do Meio Ambiente. Com isso, tem-se planejado adquirir, por meio de licitação, 1 trator sobre esteiras, 1 escavadeira hidráulica, 2 caminhões-caçamba e 8 caminhões para coleta de resíduos.

O E2 complementou dizendo que a aquisição desses caminhões permitirá reduzir os custos para os municípios consorciados e otimizar a triagem, pois os resíduos devem chegar ao consórcio com um grande potencial para reciclagem. Existe um planejamento de acordo com o qual o CIGRES passaria a fazer todo o gerenciamento dessa coleta, conforme cada município estiver disposto a aderir a esse novo sistema (E2).

Em relação à página na internet, há publicações de decretos, portarias, resoluções, licitações, notícias, entre outras informações. A organização não possui redes sociais. Os entrevistados destacam a necessidade de aprimoramento do sítio, como a implementação de um espaço público para informar os dias de coleta dos resíduos, os indicadores de geração de resíduos e as campanhas de recolhimento. Tais informações são essenciais para a consecução de indicadores para o consórcio e para os municípios, conforme apontam Ventura e Suquisaqui (2019) e Pereira e Fernandinho (2019).

Acerca dos processos internos, o E1 aponta para uma melhora, tendo em vista que o processo fícou muito mais ágil, pelo fato de o atual Presidente estar sempre em contato com o Diretor. Ademais, a aquisição de uma nova esteira de triagem com duas baias, a realização de obras de ampliação, pintura, adequações e asfaltamento da parte interna do consórcio (entre outros investimentos e obras planejadas) foram enfatizadas como melhorias pelos entrevistados. Em relação à necessidade de melhorias para os municípios consorciados, os entrevistados enfatizam a coleta seletiva e a compostagem:

A coleta eu acho, seria a coleta, organizar a coleta seria tudo. Também melhorar a participação deles (dos municípios). Antes não adiantava eles (os 
municípios) fazerem coleta seletiva lá, se aqui no consórcio não era feito bem. Hoje nós (o CIGRES) possuímos uma estrutura para poder armazenar e fazer, agora sim, se os municípios fazerem bem a coleta vai refletir em resultados muito grandes (E1).

Sobre a compostagem, o E2 menciona os seguintes impactos: redução de resíduos orgânicos; menores custos para os próprios municípios; aumento da vida útil do aterro sanitário; e aumento da quantidade de resíduo reciclado, contribuindo para o bom andamento da coleta seletiva, conforme apontam Jacobi e Besen (2011) e Alves et al. (2021). Nesse sentido, o E1 argumenta sobre a importância de os municípios realizarem campanhas que orientem a coleta de resíduos (vidros, lâmpadas e lixo eletrônico). Segundo o entrevistado, os vidros que vinham em grande quantidade para o consórcio traziam muitos prejuízos, pois furavam os pneus dos caminhões, além de prejudicarem o aterro sanitário.

Como forma de solucionar e/ou minimizar as dificuldades expostas pelos entrevistados, seria pertinente realizar reuniões com a administração de cada município e implementar um programa de benefícios/pontos que gratifique os municípios consorciados que se destacam positivamente, divulgando, assim, as boas práticas realizadas. Uma proposta interessante é desenvolver um mecanismo que conecte a sociedade com a ferramenta disponibilizada pelo Governo do Estado do Rio Grande do Sul, a "Nota Fiscal Gaúcha", de forma que a população seja reconhecida a partir de boas práticas e a educação ambiental seja trabalhada. A mudança na metodologia de cálculo reconhecendo os consorciados que trabalham corretamente na coleta seletiva - trata-se de um ponto importante para reduzir os problemas destacados.

Acrescenta-se à discussão que as medidas adotadas pelos países europeus principalmente no que se refere à responsabilização da população e dos fabricantes sobre os custos dos resíduos - contribuíram para que os países hoje sejam referência na gestão dos resíduos sólidos. Assim, pode ser uma opção a ser adotada no Brasil (Mannarino, Ferreira \& Gandolla, 2016). O sistema de coleta seletiva com contêineres que possuem sensores que avisam quando o volume de resíduos está chegando ao limit - realizado no município de Itu-SP, fruto de uma relação de parceria público e privada (Bouskela et al., 2016) - é uma prática que traz benefícios e pode reduzir as dificuldades enfrentadas pelo CIGRES. Ainda, a compostagem é uma prática que melhora o desempenho ambiental (Deus et al., 2020).

O Quadro 2 apresenta a síntese dos pontos positivos e negativos identificados no CIGRES. 
Quadro 2 - Descrição dos pontos positivos e negativos identificadas no CIGRES.

\begin{tabular}{|c|c|}
\hline Pontos Positivos & Pontos Negativos \\
\hline $\begin{array}{l}\text { O consórcio faz disposição e destinação } \\
\text { ambientalmente adequada dos resíduos, com } \\
\text { aterro sanitário licenciado e aprovado pelas } \\
\text { normas da FEPAM; }\end{array}$ & $\begin{array}{l}\text { A atual fórmula de cálculo referente à cobrança dos } \\
\text { serviços prestados pelo CIGRES, embora seja } \\
\text { padronizada para todos os municípios, não favorece } \\
\text { aqueles que enviam mais resíduos recicláveis, bem } \\
\text { como não incentiva que os municípios realizem a coleta } \\
\text { seletiva; }\end{array}$ \\
\hline $\begin{array}{l}\text { Promove a educação ambiental por meio de } \\
\text { panfletagens, seminários, reuniões e } \\
\text { assembleias, assim como desenvolve } \\
\text { trabalhos em parceria com as Emater dos } \\
\text { municípios consorciados; }\end{array}$ & $\begin{array}{l}\text { Atualmente, não é realizada a compostagem, sendo os } \\
\text { resíduos orgânicos dispostos no aterro sanitário, o que } \\
\text { se torna um grande problema; }\end{array}$ \\
\hline $\begin{array}{l}\text { O consórcio realizou importantes } \\
\text { investimentos e melhorias na estrutura, com } \\
\text { aquisição de equipamentos e melhorias nos } \\
\text { processos internos, permitindo maior } \\
\text { agilidade nas questões burocráticas; }\end{array}$ & $\begin{array}{l}\text { Embora possuam sítio oficial, há pouca utilização da } \\
\text { comunicação digital (a exemplo das redes sociais) como } \\
\text { forma de comunicação entre os municípios } \\
\text { consorciados e a população; }\end{array}$ \\
\hline $\begin{array}{l}\text { Possui Plano Intermunicipal de Gestão } \\
\text { Integrada de Resíduos Sólidos atualizado e } \\
\text { conta com a participação dos } 31 \text { municípios } \\
\text { consorciados; }\end{array}$ & $\begin{array}{l}\text { Há casos de não separação, bem como descarte incorreto } \\
\text { dos resíduos por parte da população; }\end{array}$ \\
\hline $\begin{array}{l}\text { O consórcio possui um grande quadro de } \\
\text { profissionais, o que permite atender à atual } \\
\text { demanda de serviços prestados; }\end{array}$ & relacionados à coleta e ao transporte dos \\
\hline $\begin{array}{l}\text { O consórcio definiu objetivos e metas a serem } \\
\text { alcançados a médio e longo prazo, obtendo já } \\
\text { alguns resultados positivos; }\end{array}$ & \\
\hline $\begin{array}{l}\text { O consórcio participa ativamente de reuniões } \\
\text { ou assembleias dos municípios da região, o } \\
\text { que contribui para o fortalecimento do } \\
\text { consórcio e de seus municípios consorciados. }\end{array}$ & \\
\hline
\end{tabular}

Fonte: Dados da pesquisa.

Evidentemente, a falta de separação dos resíduos dificulta o trabalho da triagem; consequentemente, há materiais que não podem ser reciclados. A necessidade de aprimorar a gestão nos municípios buscando uma visão estratégica é um ponto essencial para atingir resultados satisfatórios quanto ao correto gerenciamento (Ferreira \& Jucá, 2017).

Os pontos positivos denotam que o consórcio possui potencialidades, havendo comprometimento dos gestores quanto ao cumprimento da legislação, educação ambiental e investimentos em maquinário e infraestrutura, aspectos que se configuram como importantes mecanismos que devem ser mantidos na gestão. Outrossim, os reflexos negativos relatados pelos entrevistados podem ser minimizados por meio da revisão do cálculo de cobrança do CIGRES, de composteira e de educação ambiental para a sociedade. Saffer et al. (2013) apontam que as evidências de boas práticas são mais visíveis na região Sudeste e Sul do país, devido ao maior desenvolvimento 
socioeconômico dessas regiões. Acrescenta-se as parcerias público-privadas (Bouskela et al., 2016) como uma oportunidade de aumentar os investimentos na área em estudo.

\section{Considerações finais}

Este estudo teve por objetivo descrever as principais dificuldades e potencialidades observadas na gestão de resíduos sólidos no Consórcio Intermunicipal de Gestão de Resíduos Sólidos (CIGRES). A partir dos resultados, observa-se que o consórcio CIGRES tem trabalhado de forma efetiva para realizar a gestão de resíduos sólidos de forma eficaz. O consórcio está buscando trabalhar em parceria com os municípios consorciados e atendendo às determinações legais. Destacam-se os avanços com os investimentos em obras, maquinário, infraestrutura em geral e a preocupação com o tripé da sustentabilidade. Entretanto, ainda existem desafios que precisam ser superados.

Alguns dos aspectos que precisam ser repensados são: a fórmula de cálculo referente à cobrança dos serviços prestados; a necessidade de realizar compostagem; e a divulgação de informações de forma virtual. Em relação aos municípios consorciados, embora eles apresentem normas e legislações e campanhas de educação ambiental, há dificuldade de comunicação, falta de informações, de transporte de coleta seletiva e de compostagem. Esses são pontos fragilizados que precisam ser melhorados.

Em síntese, conclui-se que a gestão dos resíduos sólidos de forma consorciada tem se mostrado uma opção viável para municípios de pequeno porte, os quais, em sua maioria, não possuem boas condições financeiras nem profissionais capacitados para a gestão, conforme já exposto na literatura.

É importante salientar que este estudo traz contribuições teóricas e práticas sobre a temática sustentabilidade e gestão de resíduos sólidos. Na perspectiva teórica, este estudo contribui para a área de gestão de resíduos sólidos ao destacar aspectos relevantes na gestão realizada por consórcios, sendo uma forma de a Administração Pública amenizar os impactos causados pelos resíduos sólidos, considerando que há limitações financeiras para os investimentos por parte do setor público. Portanto, os consórcios públicos são uma forma eficaz para solucionar a gestão dos resíduos sólidos (Dalmo, 2021). Outrossim, este estudo traz contribuições ao entrelaçar a academia com o caso prático do CIGRES, possuindo uma relação direta com a Agenda 2030 da Organização 
das Nações Unidas (ONU), especificamente com o Objetivo do Desenvolvimento Sustentável "ODS 9 - Consumo e Produção Responsáveis".

Acerca das contribuições práticas, primeiramente, as evidências contribuem com os gestores do consórcio CIGRES. Os resultados fornecem evidências empíricas da gestão dos consórcios e o relacionamento com os municípios. Com isso, os gestores municipais podem buscar o aprimoramento de práticas. Ademais, as evidências desta pesquisa são interessantes para formuladores de políticas públicas elaborarem novas ferramentas atendendo aos Objetivos do Desenvolvimento Sustentável, bem como integrarem o conceito de 'cidades sustentáveis'.

Como limitação, este estudo não permite generalizações, pois analisou apenas um consórcio e utilizou somente duas fontes de evidencias (entrevistas e análise documental). Pesquisas futuras podem analisar a viabilidade da geração de energia a partir dos RSU como fonte de receita (Dalmo et al., 2019) para a região Sul do Brașil. Investigações futuras também podem integrar inovação e tecnologia, propondo iniciativas para as "cidades inteligentes". Sugere-se a ampliação de estudo com outros consórcios intermunicipais de gerenciamento de resíduos sólidos a fím de comparar as práticas executadas e identificar possíveis dificuldades ou potencialidades semelhantes, permitindo uma maior generalização dos resultados (inclusive com enfoque quantitativo). Comparações entre países em desenvolvimento e países desenvolvidos permitem a análise de outras práticas de gestão para os resíduos sólidos.

\section{Referências}

Almeida, G. G. F. de., Silveira, R. C. E. da., \& Engel, V. (2020). Coleta e reciclagem de resíduos sólidos urbanos: contribuição ao debate da Sustentabilidade Ambiental.

Future Studies Research Journal: Trends and Strategies, 12 (2).

https://doi.org/10.24023/FutureJournal/2175-5825/2020.v12i2.445

Alves, R. C. et al. (2020). A (in) viabilidade dos Consórcios Públicos Intermunicipais para Gestão de Resíduos Sólidos no Amazonas, Brasil. Research, Society and Development, 9 (11), e82191110582-e82191110582.

http://dx.doi.org/10.33448/rsd-v9i11.10582

Bardin, L. (2016). Análise de conteúdo. [Tradução de] Luís Augusto Pinheiro. São Paulo: Edições, 70.

Brasil. (2010a, 2 de agosto). Lei $n^{\circ} 12.305$ de 2 de agosto de 2010. Institui a Política Nacional de Resíduos Sólidos; altera a Lei no 9.605, de 12 de fevereiro de 1998; e 
dá outras providências. Recuperado em 05 de outubro de 2019, de http://www.planalto.gov.br/ccivil_03/_ato2007-2010/2010/lei/112305.htm

Brasil. (2010b, 23 de dezembro). Decreto $n^{\circ} 7.404$ de 23 de dezembro de 2010. Regulamenta a Lei no 12.305, de 2 de agosto de 2010. Recuperado em 10 de janeiro de 2021, de http://www.planalto.gov.br/ccivil_03/_ato20072010/2010/decreto/d7404.htm

Brasil. (2007, 17 de janeiro). Decreto $n^{\circ} 6.017$ de 17 de janeiro de 2007. Regulamenta a Lei no 11.107, de 6 de abril de 2005, que dispõe sobre normas gerais de contratação de consórcios públicos. Recuperado em 10 de janeiro de 2021, de http://www.planalto.gov.br/ccivil_03/_ato2007-2010/2007/decreto/d6017.html

Bouskela, M., Casseb, M., Bassi, S., De Luca, C., \& Facchina, M. (2016). La ruta hacia las Smart Cities: Migrando de una gestión tradicional a la ciudad intelgiente. Banco Interamericano de Desarrollo.

Calderan, T. B. (2013). Consórcio Público Intermunicipal de Gerenciamento de Resíduos Sólidos Domésticos: um estudo de caso. Dissertação (Mestre em Ambiente e Desenvolvimento, na área de Concentração Espaço, Ambiente e Sociedade). Programa de Pós-Graduação em Ambiente e Desenvolvimento, do Centro Universitário Univates. Lajeado.

Calderan, T. B. (2018). Consórcios intermunicipais: condições e possibilidades de atendimento da Política Nacional de Resíduos Sólidos (PNRS) a partir do princípio da visão sistêmica. Tese (Doutorado em Ambiente e Desenvolvimento). Programa de Pós-Graduação em Ambiente e Desenvolvimento, do Centro Universitário Univates. Lajeado.

CIGRES (2010). Consórcio Intermunicipal de Gestão de Resíduos Sólidos. Estatuto Alteração Estatutária n. 2. Recuperado em 21 de dezembro de 2021, de http://cigres.com.br/arquivos/ESTATUTO.pdf

CIGRES (2019). Consórcio Intermunicipal de Gestão de Resíduos Sólidos. Plano Intermunicipal de Gestão Integrada de Resíduos Sólidos. Recuperado em 21 de dezembro de 2021, de https://cespro.com.br/7711/2019_L1941.pdf

CIGRES (2012). Consórcio Intermunicipal de Gestão de Resíduos Sólidos. Plano Regional de Gestão Integrada de Resíduos Sólidos dos Municípios Integrantes do Consórcio Intermunicipal de Gestão de Resíduos Sólidos. Recuperado em 30 de setembro de 2019, de http://www.cigres.com.br/portal/?mn=prgirs

Cetrulo, T. B. et al. (2018). Eficácia das políticas de resíduos sólidos em países em desenvolvimento: um estudo de caso no Brasil. Jornal de produção mais limpa, 205, 179-187. https://doi.org/10.1016/j.jclepro.2018.09.094

Dalmo, F. C., Simao, N., Nebra, S., \& Santana, P. D. M. (2019). Energy recovery from municipal solid waste of intermunicipal public consortia identified in São Paulo State. Waste Management \& Research, 37(3), 301-310. 
Deus, R. M. et al. (2020). A municipal solid waste indicator for environmental impact: Assessment and identification of best management practices. Journal of Cleaner Production, 242, 118433. http://dx.doi.org/10.1016/j.jclepro.2019.118433

Ferreira, C. F. A., \& Jucá, J. F. T. (2017). Metodologia para avaliação dos consórcios de resíduos sólidos urbanos em Minas Gerais. Engenharia Sanitária e Ambiental, 22 (3), 513-521. https://doi.org/10.1590/S1413-41522017147551

Fidelis, R. et al. (2020). Socio-productive inclusion of scavengers in municipal solid waste management in Brazil: Practices, paradigms and future prospects. Recursos, Conservação e Reciclagem, 154, 104594. https://dx.doi.org/10.1016/j.resconrec.2019.104594

Gomes, A. P. et al. (2017). Panorama dos Consórcios Intermunicipais para Gestão de Resíduos Sólidos Urbanos no Estado do Rio Grande Do Sul. In: II Simpósio Brasileiro de Desenvolvimento Territorial Sustentável. Paraná. Recuperado em 10 de janeiro de 2021, de http://www.ppgdts.ufpr.br/?page_id=1464

Heber, F., \& Silva, E. M. (2014). Institucionalização da política nacional de resíduos sólidos: Dilemas e constrangimentos na região metropolitana de Aracaju (SE). Revista de Administração Pública, 48(4), 913-937. https://doi.org/10.1590/0034-76121537

IBGE. (2010). Instituto Brasileiro de Geografia e Estatística. Censo Demográfico 2010. Rio de Janeiro: IBGE. Recuperado em 25 de outubro de 2019, de http://www.censo2010.ibge.gov.br

Jacobi, P. R., \& Besen, G. R. (2011). Gestão de resíduos sólidos em São Paulo: desafios da sustentabilidade. Estudos Avançados, 25 (71), 135-158. https://doi.org/10.1590/S0103-40142011000100010

Leal, T. L. M. de C., \& Sampaio, R. J. (2021). Gestão dos resíduos sólidos: o caso do consórcio de desenvolvimento sustentável do alto sertão na Bahia. urbe. Revista Brasileira de Gestão Urbana, 13. https://doi.org/10.1590/21753369.013.e20180123

Liikanen, M. et al. (2018). Steps towards more environmentally sustainable municipal solid waste management-A life cycle assessment study of São Paulo, Brazil. Journal of Cleaner Production, 196, 150-162. https://doi.org/10.1016/j.jclepro.2018.06.005

Lisbinski, F. C. et al. (2020). A importância dos consórcios públicos na gestão dos resíduos sólidos urbanos: uma análise do consórcio intermunicipal CIGRES. Revista Gestão \& Sustentabilidade Ambiental, 9 (2), 3-36. http://dx.doi.org/10.19177/rgsa.v9e220203-36

Luiz, G. de C. (2018). Política Nacional de Resíduos Sólidos: uma análise da gestão em municípios de pequeno porte. Dissertação (Mestrado em Gestão de Organizações Públicas). Programa de Pós-Graduação em Gestão de Organizações Públicas, da Universidade Federal de Santa Maria. 
Mannarino, C. F., Ferreira, J. A., \& Gandolla, M. (2016). Contribuições para a evolução do gerenciamento de resíduos sólidos urbanos no Brasil com base na experiência Européia. Engenharia Sanitária e Ambiental, 21, 379-385.

ONU. Organização das Nações Unidas. Agenda 2030. Recuperado em 21 de dezembro de 2021, de https://brasil.un.org/pt-br/sdgs.

Penteado, C. S. G., \& Castro, M. A. S. (2021). Efeitos de Covid-19 na gestão de resíduos sólidos urbanos: o que efetivamente pode ser feito no cenário brasileiro?. Recursos, Conservação e Reciclagem, 164, 105152. https://doi.org/10.1016/j.resconrec.2020.105152

Pereira, T. S., \& Fernandino, G. (2019). Evaluation of solid waste management sustainability of a coastal municipality from northeastern Brazil. Ocean \& Coastal Management, 179. https://doi.org/10.1016/j.ocecoaman.2019.104839

Saffer, M. et al. (2013). Boas práticas Brasil e Espanha sobre a gestão de resíduos sólidos urbanos com foco na coleta seletiva, reciclagem e participação dos catadores. Fundação Instituto para o Fortalecimento das Capacidades Institucionais - IFCI / Agência Espanhola de Cooperação Internacional para o Desenvolvimento - AECID / Ministério do Planejamento, Orçamento e Gestão - MPOG, Editora IABS, Brasília.

Sampieri, R. H., Collado, C. F., \& Lucio, M. del. P. B. (2013). Metodologia da Pesquisa. 5. Ed. Porto Alegre: Penso.

SNIS (2019). Sistema Nacional de Informações sobre Saneamento. Diagnóstico do Manejo de Resíduos Sólidos Urbanos - 2018. Brasília. Recuperado em 20 de outubro de 2019, de http://www.snis.gov.br/diagnostico-residuos-solidos

Ventura, K. S., \& Suquisaqui, A. B. V. (2020). Aplicação de ferramentas SWOT e 5W2H para análise de consórcios intermunicipais de resíduos sólidos urbanos. Ambiente construído, 20 (1), 333-349. https://doi.org/10.1590/s167886212020000100378

Yin, R. K. (2015). Estudo de caso: planejamento e método. 5.ed. Porto Alegre: Bookman.

Zago, V. C. P., \& Barros, R. T. V. (2019). Gestão dos resíduos sólidos orgânicos urbanos no Brasil: do ordenamento jurídico à realidade. Eng Sanit Ambient, 24 (2), 219-228. https://doi.org/10.1590/S1413-41522019181376 


\section{Anexo 1 - Roteiro Entrevista}

Nome:

Cargo/Função:

Formação:

Data:

E-mail para contato:

Telefone para contato:

1. Discorra livremente sobre a estrutura física do Consórcio CIGRES, apontando as atividades realizadas, os resíduos recebidos e os profissionais trabalham no consórcio.

2. Discorra livremente sobre como funciona a gestão dos resíduos sólidos realizada pelo Consórcio CIGRES e como funciona o trabalho com os municípios consorciados.

3. O consórcio possui o Plano Regional de Gestão Integrada de Resíduos Sólidos? Quando foi criado? Foi atualizado? Todos os municípios consorciados fazem parte do plano?

4. Como funciona a questão dos custos? Quanto cada município paga por tonelada de resíduo enviado? É por quilo?

5. Em relação aos resíduos recicláveis, o município recebe algum tipo de desconto ou benefício por quantidade de resíduo reciclável que envia ao consórcio?

6. O CIGRES tem um retorno financeiro com a venda dos reciclados?

7. Quais as vantagens que você considera possíveis de alcançar por meio do consorciamento?

8. Quais as dificuldades encontradas no modelo de consórcio adotado pelo CIGRES?

9. Na sua opinião, em municípios de pequeno porte (como é o caso da maioria dos municípios consorciados do CIGRES), quais são os desafios para a efetivação de uma gestão de resíduos plena?

10. Em sua opinião, quais são as melhores práticas a serem executadas pelos municípios de pequeno porte consorciados ao CIGRES para terem uma plena gestão de resíduos sólidos?

11. Discorra abertamente sobre os municípios consorciados. (Potencialidades, dificuldades, críticas, pontos positivos, dúvidas. Exponha informações que, em sua opinião, são importantes para o consórcio ou para os municípios). 